\title{
Оценка кредитного дефолтного свопа на российские компании при помощи редуцированной модели и модели Мертона
}

\author{
Мезенцев В.В. ${ }^{10}$
}

Кредитный дефолтный своп является инструментом оценки участниками рынка кредитного риска компании. $B$ данной статье рассматривается применение редуцированной модели и структурной модели (модели Мертона) для оценки кредитных свопов на российские компании и банки: «Газпром», “Сбербанк», ВТБ, «Транснефть» $u$ «Северсталь». Делаются выводы о точности оченки каждой модели и приводятся методы, с помощью которых можно увеличить предсказательную силу моделей.

JEL: $G 12, C 23$

Ключевые слова: кредитный дефолтный своп, кредитный риск, модель Мертона, структурные модели, редуцированные модели

\section{Введение}

Оценка кредитного риска компании является одним из основных компонентов инвестиционного процесса и используется практически во всех сферах финансовой и экономической деятельности. Инвестирование в долговые инструменты или продукты требует оценивать кредитный риск, например для покупки облигации и векселей, для открытия кредитных линий, синдицированного кредитования, сделок РЕПО или лизинга. Также кредитные риски актуальны для сделок по слиянию и поглощению (М\&A сделки), для коммерческой деятельности, например для отгрузки покупателю товара или сырья в рассрочку. Даже при инвестировании в инструменты, которые сами по своей природе не содержат кредитного риска, часто необходимо его оценивать. Например, все внебиржевые срочные инструменты содержат контрагентский риск, который является не чем иным, как кредитным риском противоположной стороны в сделке. И даже акции косвенно несут в себе кредитный риск эмитента, поскольку, как показывают структурные модели, между долговыми и долевыми инструментами одного эмитента наблюдается ярко выраженная взаимосвязь.

Существует множество способов оценить кредитный риск компании, например с помощью кредитных рейтингов общепризнанных рейтинговых агентств или внутренних систем кредитного анализа. Поскольку кредитный риск в широком смысле является вероятностью дефолта компании, то с помощью различных моделей, таких как модель Альтмана, можно измерить кредитный риск в абсолютных величинах.

Но мировой финансовый кризис 2008-2009 годов показал, что современные условия существования финансового рынка требуют других подходов и способов оценки кредитных рисков. Например, в сентябре 2009 года Moody's понизило рейтинг Lehman Brothers Holdings Inc. и его дочерних компаний сразу на 10 пунктов - с A2 до B3, а вслед за Moody's, Fitch понизил долгосрочный рейтинг дефолта эмитента с A+ до D. Значит, в какой-то момент рейтинг явно не отражал реальное положение дел.

У первой жертвы вышеназванного кризиса, инвестбанка Bear Stearns, за несколько недель до банкротства кредитный рейтинг был на уровне кредитного рейтинга России. Это говорит о том, что традиционные методы оценки кредитного риска имеют слишком большой временной лаг, и даже дневное запаздывание оценки риска может привести к фатальным последствиям.

\footnotetext{
${ }^{10}$ Аспирант НИУ ВШЭ.
} 
На финансовом рынке существуют инструменты, которые отражают рыночную оценку кредитного риска какой-либо долговой ценной бумаги, целого портфеля, отдельной компании или государства практически в режиме реального времени, - это кредитные дефолтные свопы (Credit Default Swap - CDS).

Существенный плюс CDS в том, что их одновременно и непрерывно оценивают сотни участников рынка, которые берут во внимание не только отчетность компании, ее кредитные рейтинги, другие фундаментальные оценки, но и всю вновь поступающую информацию. Это значительно увеличивает гибкость в оценке кредитного риска относительно использования рейтингов или отчетности, поскольку последние обновляются, как правило, ежеквартально. В отличие от облигаций, которые являются все же долговым инструментом, CDS в чистом виде - это рыночный инструмент оценки кредитного риска.

Проблема оценки кредитного дефолтного свопа в настоящее время не разрешена: нет единого подхода, либо устоявшейся модели оценки CDS, подобно модели Блэка-Шоулза для опционов. В данной статье мы сравним применимость двух основных типов моделей для оценки кредитного дефолтного свопа на российские компании: структурных моделей (модели Мертона) и редуцированных моделей.

Вопрос, какая модель лучше отражает справедливую стоимость CDS, до сих пор является предметом научных споров в западной литературе. Мы, используя исторические данные, применим поочередно каждую модель для оценки CDS на российские компании и сравним результаты с рыночными котировками CDS. Тем самым мы ответим на два вопроса: применимы ли общеизвестные западные модели для оценки CDS на российские компании и какая из моделей лучше оценивает кредитный риск компаний.

\section{Кредитный дефолтный своп, его особенности и рынок кредитных свопов, выписанных на российские компании}

Кредитный дефолтный своп - это договор между двумя контрагентами, финансовыми институтами, по которому одна сторона выплачивает другой определенную сумму, при наступлении кредитного события у третьей стороны или у определенного набора финансовых активов - базового портфеля. Кредитным событием может служить дефолт компании или государства, резкое снижение цен акций или облигаций компании, невыплата или задержка купона или номинала по облигациям, изменение кредитного рейтинга, реструктуризация задолженности. Таким образом, CDS по своей сути - страховка от потерь по финансовому инструменту.

Схема выпуска CDS представлена на рисунке 1.

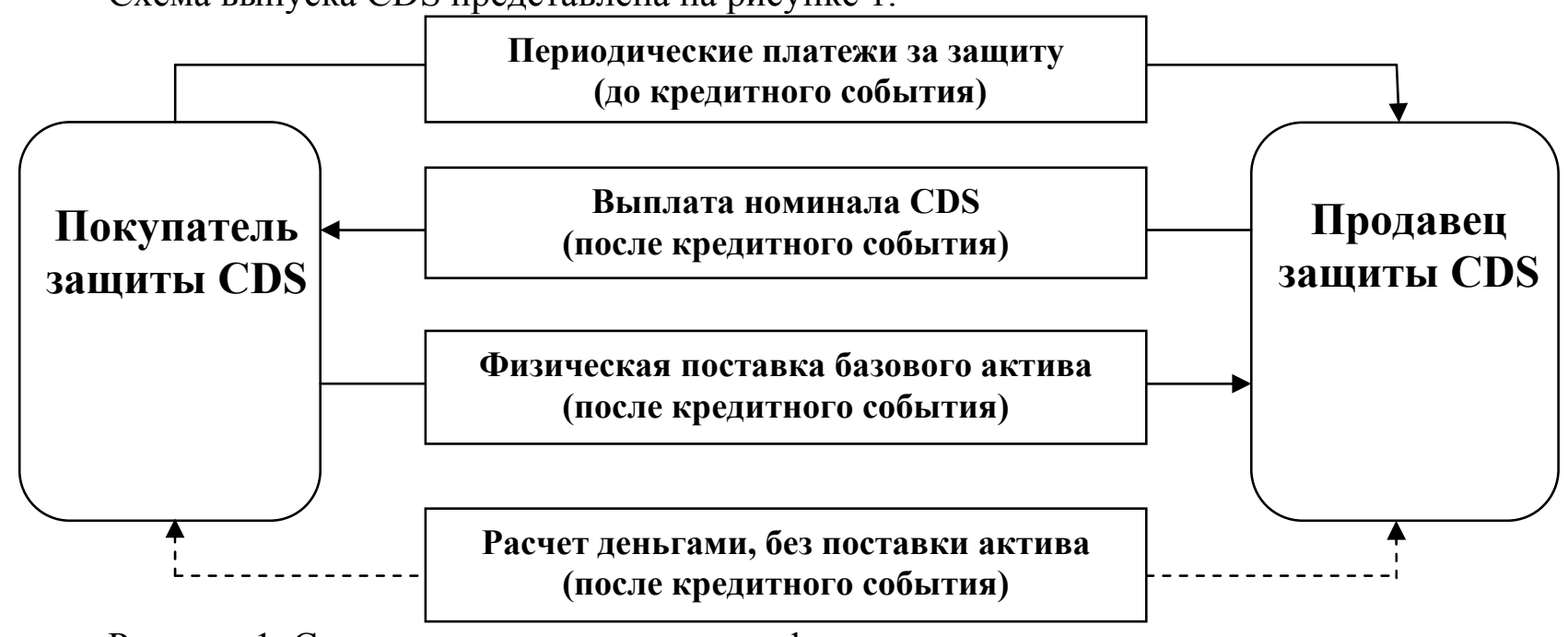

Рисунок 1. Схема выпуска кредитного дефолтного свопа

В случае дефолта базового актива, на который выписан CDS, расчет может 
производиться физической поставкой базового актива покупателем защиты в обмен на номинал CDS либо денежным расчетом, когда продавец защиты выплачивает покупателю разницу между номиналом CDS и ликвидационной стоимостью базового актива (покрытием).

\section{История появления и развития инструмента, глобальный рынок CDS}

Кредитные деривативы (или синтетическая секьюритизация) возникли в начале 1990-х годов. Изначально это были отдельные, неизвестные широкой публике сделки, в которых одна сторона принимала на себя риски долгового портфеля другой в обмен на вознаграждение. Затем такие договоры стали полноценными финансовыми инструментами, а синтетическая секьюритизация - сегментом финансового рынка.

Развитию рынка синтетической секьюритизации способствовало изменение регулятивных норм в области банковского законодательства. Согласно международному соглашению Базель II, капитал банка должен быть не менее $8 \%$ от величины активов, что эквивалентно кредитному рычагу 12,5:1. Известно, что выданные кредиты или приобретенные облигации обязывают банк резервировать часть средств на возможные потери. Но если переложить риски на другое лицо, снять их с баланса, то можно высвободить резервы и продолжать наращивать масштабы деятельности. Перед банками возникла задача найти механизм «снятия» кредитного риска портфеля кредитов и облигаций с баланса. В качестве решения данной проблемы были предложены инструменты и технологии с невиданными до тех пор возможностями по управлению рисками.

Первые упоминания о кредитном дефолтном свопе были зафиксированы в 1994 году, а первым всемирно известным участником рынка, который широко использовал CDS в качестве инструмента страхования кредитного портфеля, стал банк J.P. Morgan. В декабре 1997 года специалисты этого инвестбанка скомпоновали несколько сотен кредитов, выданных крупным компаниям, выделили из них наиболее рискованные и фактически объявили, что J.P. Morgan обязуется регулярно выплачивать вознаграждение тому, кто возьмет на себя риск невыплат данных компаний. Это была первая публичная сделка CDS. До этого данный инструмент существовал в форме двусторонних договоров, которые не раскрывались широкой публике.

Таким образом, CDS изначально был создан как инструмент хеджирования кредитного риска и инструмента передачи кредитного риска актива между контрагентами за плату. Но достаточно быстро CDS стал спекулятивным инструментом, его начали использовать для игры на колебаниях цены, и на данный момент сферу применения CDS можно условно разделить на три части:

1. Хеджирование кредитного риска инструмента, на который выписан CDS. B данном случае покупателями CDS выступают держатели рискового актива, который приобретает CDS на сумму не более величины долга. Если банк приобрел на 50 млн долл. облигаций какой-либо компании, то для хеджирования кредитного риска он может приобрести CDS на сумму 50 млн долл. по номинальной стоимости.

Данный сегмент рынка CDS не является преобладающим по объему. Например, в 2007 объем CDS на дефолт американской компании «Дженерал Моторс» превышал 2 трлн долл., при том что совокупный долг компании не превышал несколько сотен миллиардов долларов. Очевидно, что среди покупателей CDS были и те, кто не приобрел их для хеджирования кредитного риска «Дженерал Моторс».

2. Хеджирование других инструментов за счет CDS.

Участники рынка выявили ряд закономерностей, когда цена CDS сильно коррелирует с ценами на те или иные активы. В таблице 1 приведены коэффициенты корреляции между динамикой цен CDS на Россию и на три российские компании за 2007-2010 годы. 
Коэффициенты корреляции между спредами CDS на российский суверенный долг и спредами CDS на компании

\begin{tabular}{|c|c|}
\hline Пары CDS & $\mathbf{P , ~ \%}$ \\
\hline Россия-Газпром & 99,12 \\
\hline Россия-Сбербанк & 98,99 \\
\hline Россия-ВТБ & 96,73 \\
\hline
\end{tabular}

Таким образом, при помощи CDS можно хеджировать риски по другим инструментам. Например, трейдер видит рост доходностей облигаций на рынке, расширение спредов, резкое падение цен на акции, но он считает, что это краткосрочное явление, вызванное уменьшением ликвидности или негативными новостями, а не начинающейся долгосрочной рецессией экономики. При этом у него достаточно большой портфель низко- или среднеликвидных облигаций российских эмитентов, CDS на которые не выпускались. Продавая облигации на рынке, он много потеряет на bid/offer-спреде, или ему придется отдавать существенную премию за большой объем продажи. В этой ситуации он может купить CDS на Россию, и его позиция будет в достаточной степени захеджирована ликвидным инструментом.

3. Спекулятивная торговля CDS.

В качестве инструмента для спекуляций CDS стал выступать достаточно быстро, через 3-5 лет от момента его возникновения. Этому, на наш взгляд, способствовали следующие факторы. Во-первых, дефолтные свопы начали становиться ликвидными, то есть возник вторичный рынок CDS между теми, кто хеджировал свои долговые инструменты. Во-вторых, за счет CDS легко было создать значительное плечо. Поскольку дефолтный своп - это дериватив на кредитное событие, покупателю надо лишь инвестировать какую-то долю средств от общего номинала CDS. В-третьих, рынок стал регулируемым, регулятором выступила Международная ассоциация по свопам и деривативам (ISDA), которая имеет большой авторитет среди участников рынка. С появлением первых спекулянтов начала увеличиваться ликвидность и волатильность рынка, что привело еще больше спекулянтов на рынок CDS.

Из таблицы 2 и графика 1 видно, что рынок CDS достигает несколько десятков триллионов долларов США, что подтверждает факт наличия большой спекулятивной составляющей на рынке кредитных деривативов.

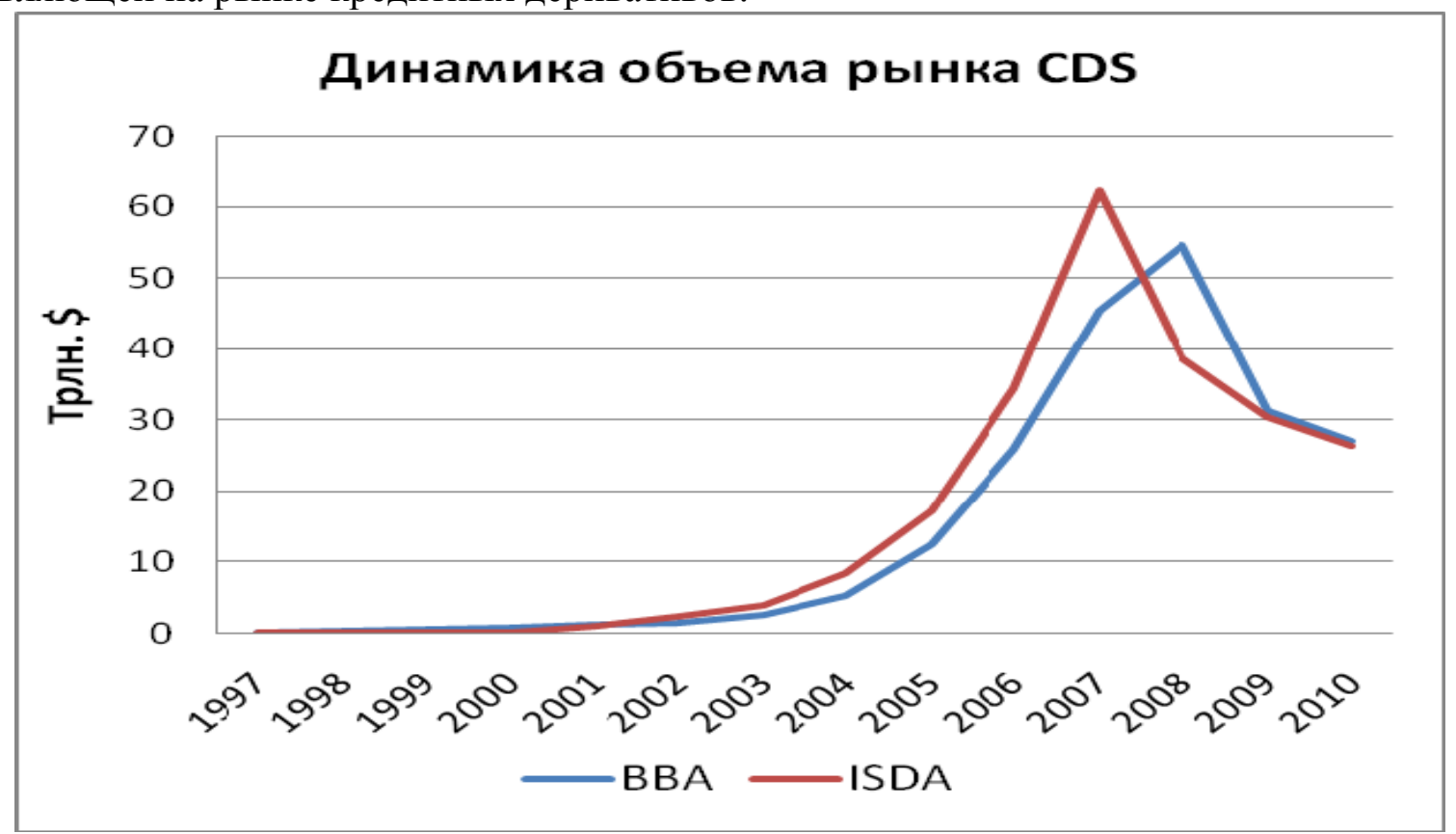

График 1. Динамика рынка CDS 
Объем рынка CDS в 1997-2010 годах, трлн долл.

\begin{tabular}{|l|l|l|}
\hline Год & ВBA $^{11}$ & ISDA $^{12}$ \\
\hline 1997 & 0,18 & - \\
\hline 1998 & 0,35 & - \\
\hline 1999 & 0,59 & - \\
\hline 2000 & 0,89 & - \\
\hline 2001 & 1,19 & 0,92 \\
\hline 2002 & 1,60 & 2,19 \\
\hline 2003 & 2,69 & 3,78 \\
\hline 2004 & 5,44 & 8,42 \\
\hline 2005 & 2,43 & 17,10 \\
\hline 2006 & 26,00 & 34,40 \\
\hline 2007 & 45,46 & 62,20 \\
\hline 2008 & 54,60 & 38,60 \\
\hline 2009 & 31,20 & 30,40 \\
\hline 2010 & 27,10 & 26,20 \\
\hline
\end{tabular}

С одной стороны, спекулянты создают ликвидность, с другой - они раздувают рынок, создавай «мыльный пузырь» и «перегревая» справедливые цены CDS.

\section{Рынок CDS на российские компании}

Рынок CDS на российские долговые инструменты и кредитный риск компаний существует, также существует CDS на российский суверенный долг. Индикативные котировки можно найти в информационных системах, например Bloomberg, либо на различных сайтах по долговым инструментам.

Особенность рынка CDS на российские компании в том, что CDS есть только на те компании, еврооблигации которых обращаются на рынке, поскольку рынок CDS представлен преимущественно западными игроками и дефолтные свопы котируются в долларах или евро, а значит, они интересны для хеджирования именно валютного долга. Кроме того, организаторами выпуска еврооблигаций являются исключительно известные и уважаемые финансовые институты, которые проводят тщательный анализ эмитента, а отчетность аудируется компаниями Big4, то есть у западных игроков появляется определенная база для анализа кредитного качества эмитента и его долга.

В данный момент в обращении находятся еврооблигации порядка 70 российских эмитентов, но CDS существуют только на 7-10 компаний, при этом относительно ликвидными являются только трех- или пятилетние CDS на «Газпром», «Сбербанк» и ВТБ. Дефолтные свопы на такие компании, как «Лукойл», «Северсталь», «Россельхозбанк», «Транснефть», «Вымпелком», РЖД, ТНК-ВР, ТМК, «Евраз» или МТС, обладают гораздо меньшей ликвидностью.

\footnotetext{
11 Данные Британской банковской ассоциации (BBA - British Bankers Association).

12 Данные Международной ассоциации свопов и деривативов (ISDA - International Swap Derivative Association).
} 


\section{Модели оценки кредитного дефолтного свопа}

Существуют следующие модели для оценки кредитного дефолтного свопа:

1. Оценка CDS на основе стоимости хеджирования.

2. Модели оценки CDS, основанные на интенсивности дефолтов, упрощенные или редуцированные модели.

3. Модели оценки кредитных инструментов на основе кредитного рейтинга.

4. Структурные модели оценки CDS или модели, основанные на стоимости фирмы.

Первые две модели не используют фундаментальных показателей компании, а лишь стоимость/доходность уже обращающихся инструментов, например облигаций. То есть полученный с их помощью результат является производным от оценок других инструментов.

Структурные модели и модели на основе кредитного рейтинга в своей основе используют фундаментальные показатели компании. Таким образом, структурные модели опираются на финансовое положение компании или на показатели ее отчетности, а редуцированные - на рыночную оценку других обращающихся долговых инструментов компании.

\section{Структурные модели. Суть подхода Мертона}

В 1973 году Блэк и Шоулз (Black and Scholes, 1973), а затем и Мертон (Merton, 1974), предложили простую модель, которая обеспечивает связь кредитного риска со структурой капитала фирмы. Изначально модель Блэка-Шоулза использовалась для оценки опционов, но именно Роберт Мертон впервые применил теорию опционов к проблеме оценки обязательств фирмы при наличии дефолта. Данная модель может применяться для оценки любых существующих на данный момент видов кредитных деривативов, в частности CDS.

Если сказать кратко, то структурные модели задают или определяют условия, при которых с экономической точки зрения ожидается, что компания подвергнется дефолту. Затем вычисляется вероятность того, что эти условия наступят. Зная вероятность дефолта и ожидаемый поток от CDS в случае наличия и отсутствия дефолта по базовому активу, можно оценить рисковый инструмент.

Из корпоративных финансов известно следующее соотношение:

(1) Рыночная стоимость активов = Капитализация + Стоимость долга

Известно, что держатели долговых инструментов имеют первоочередное право на получение инвестированных в компанию средств, а только потом свои средства получают акционеры. Таким образом, капитализация - остаточная стоимость компании или то, что остается после выплаты долговых обязательств. Следовательно, теоретически капитализация может быть отрицательной величиной, если стоимость активов меньше долговых обязательств. В случае если существует акционерный капитал с отрицательной стоимостью, то акционеры могут избавиться от него без каких-либо издержек для себя. Иначе говоря, акционеры не реализуют опцион-колл и оставляют фирму кредиторам - держателям долга, и в этом случае компания объявляет дефолт.

Вышесказанное можно выразить формулой:

$$
S(V, T)=\max (0, V(T)-D),
$$

где:

$S(V, T)$ - стоимость акционерного капитала в момент времени $T$,

$V(T)$ - стоимость фирмы в момент времени $T$,

$D$ - номинальная стоимость долга.

Из формулы (2) видно, что стоимость акционерного капитала представляет собой опцион-колл на стоимость фирмы с ценой исполнения, равной номинальному размеру долга.

Отсюда рисковый долг можно представить следующим соотношением

$$
\mathbf{E}(V, t, T)=\min (D, V(T))=D-\max (0, D-V(T)),
$$


где $\mathbb{E}(V, t, T)$ - рыночная стоимость долга на момент погашения.

Таким образом, рыночную стоимость долга компании можно представить как портфель, состоящий из дисконтной облигации с номиналом D и короткого опциона путь на стоимость фирмы с ценой исполнения D.

Для расчета стоимости акционерного капитала и рискового долга компании используется классическая формулу Блэка-Шоулса:

$$
\begin{aligned}
& S_{0}=B S_{e a n}\left(\sigma_{y}, T, B(0, T), r_{2} V_{0}\right)=V_{0} N\left(d_{1}\right)-B(0, T) * N\left(d_{2}\right)
\end{aligned}
$$

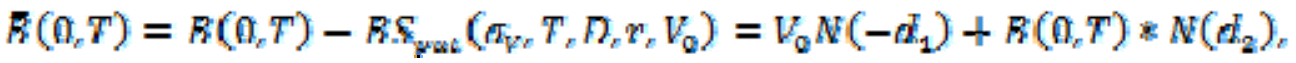

где:

$$
\begin{gathered}
d_{1}=\frac{\ln \left(\frac{V_{0}}{D}\right)+\left(r+0.5 \sigma_{V}^{2}\right)}{\sigma_{V} \sqrt{T}} \\
d_{2}=d_{1}-\sigma_{V} \sqrt{T} \\
B(0, T)=D e^{-r t} .
\end{gathered}
$$

Из выражения (5) мы получим следующие соотношения для расчета кредитного спреда:

$$
\begin{gathered}
\frac{\bar{B}(0, T)}{B(0, T)}=N\left(d_{1}-\sigma_{V} \sqrt{T}\right)-\frac{V_{0}}{D e^{-r T}} N\left(-d_{1}\right) \\
c(T)=-\frac{\ln \left(N\left(d_{1}-\sigma_{V} \sqrt{T}\right)+\frac{V_{0}}{D e^{-r T}} N\left(-d_{1}\right)\right)}{T},
\end{gathered}
$$

где $c(T)$ - кредитный спред долгового инструмента или стоимость CDS.

В выражении (7) нам неизвестно значение $\sigma_{V}$ - волатильности стоимости фирмы. На основании того, что стоимость акционерного капитала является производной от стоимости фирмы, в 1984 года Джонс, Мэсон и Розенфельд [Jones, Mason and Rosenfeld, 1984], используя лемму Ито, вывели следующее соотношение, связывающее волатильность акций и стоимости компании:

$$
\sigma_{V}=\sigma_{A} \frac{N\left(d_{1}\right)-L N\left(d_{2}\right)}{N\left(d_{1}\right)} .
$$

Опишем более подробно детерминанты модели Мертона и их вклад в формирование стоимости CDS.

Доля долга в стоимости компании (Debt to Value Ratio - Debt/EV). Debt/EV определяется как отношение долга компании к стоимости компании. Debt/EV рассчитывается по формуле:

(9) Балансовая стоимость обязательств / (Капитализация + Чистый долг компании).

Модель Мертона подразумевает, что дефолт происходит в случае, если стоимость фирмы падает ниже стоимости ее долга. Следовательно, чем больше Debt/EV, тем больше вероятность дефолта. Если долг увеличивается на величину, превышающую стоимость фирмы, а другие переменные остаются неизменными, тогда цена опциона-пут (и кредитного спреда) увеличится. Чем больше Debt/EV, тем более вероятно, что случится дефолт и, соответственно, тем более дорогой должна быть страховка от дефолта. Стоимость этой страховки отражается в динамике цены CDS. Tем самым, спред CDS должен увеличиваться при увеличении рычага. Эмпирические исследования подтверждают положительную связь между величиной Debt/EV и кредитными спредами.

Волатильность. Основываясь на теории опционов, цена опциона должна возрастать с ростом волатильности базового актива. Возросшая волатильность увеличивает вероятность дефолта, что в свою очередь увеличивает стоимость страховки от дефолта, отражаемой 
кредитным спредом. Значения исторической волатильности базируются на исторических котировках акций. Историческая волатильность в данном случае была подсчитана как стандартное отклонение доходности акций в течение 90 дней. Модель Мертона очень сильно зависит от волатильности, поэтому расчет волатильности является ключевым моментом реализации модели.

Безрисковая ставка. В качестве безрисковой ставки мы используем значение доходности бескупонной казначейской облигации США сроком в один год. Более высокая ставка ведет к большему ожидаемому темпу роста фирмы, что снизит вероятность дефолта и уменьшит кредитный спред. Таким образом, спред CDS должен снижаться с увеличением безрисковой ставки.

\section{Редуцированные модели на основе кредитного спреда и стоимости облигации}

Между ценой рисковой дисконтной облигации и вероятностью дефолта существует фундаментальная зависимость.

$$
1-P(t, T)=\frac{\bar{B}(t, T)}{B(t, T)},
$$

где:

$T$ - срок погашения облигации; $\bar{B}(t, T)$ sassxsddsaasss_ цена рисковой дисконтной облигации в момент времени $t$;

$B(t, T)$ _ цена безрисковой дисконтной облигации в момент времени $t$;

$P(t, T)$ - вероятность что дефолта рисковой дисконтной облигации не произойдет за период от $t$ до $T$.

То есть $1-P(t, T)$ есть вероятность дефолта облигации в период между временем $t$ и сроком погашения облигации.

Данная зависимость была отражена в ряде работ западных авторов, например Даффи (Duffie, 1999).

Таким образом, стоимость дисконтной рискованной облигации равна стоимости аналогичной безрисковой, умноженной на вероятность дефолта.

Суть модели заключается в том, что «справедливую» цену инструмента можно получить при равенстве ожидаемых потоков для продавца и покупателя этого инструмента. Поскольку с помощью цен дисконтной рисковой и безрисковой облигации можно определить вероятность дефолта базового актива, стоит оценить вероятный денежный поток покупателя и продавца защиты. Единственный оценочный параметр в данном методе коэффициент покрытия, часть номинала облигации, которую получает ее держатель при дефолте эмитента.

Все полученные стоимости потоков должны быть приведены к одному моменту времени с помощью безрисковой ставки. При этом должна быть учтена вероятность совершения платежа, или фактически вероятность дефолта в каждом отдельном периоде.

Оценка вероятности риска по формуле (4) предполагает то, что спред между облигациями обусловлен только кредитным риском. Таким образом, временная структура спредов рисковой облигации относительно безрисковой является временной структурой вероятностей дефолта рисковой облигации.

Приведенная стоимость периодических платежей продавца защиты выражается формулой:

$$
S_{w}=\sum_{w-1}^{N}\left(\prod_{2}^{n} P\left(t_{w-2}, t_{w-1}\right)\right) s * e^{-m n}
$$

где:

$s$ - стоимость CDS в процентах от номинала облигации; 
$r$ - непрерывная безрисковая ставка дисконтирования;

$n$ и $N$ - период платежа и общее количество периодов (срок контракта);

$e^{-m}$ - дисконтирующий коэффициент по непрерывной годовой ставке $r$;

$P\left(t_{n-2}, t_{n-1,}\right)$ - вероятность того, что по рисковой дисконтной облигации в период времени $\left(t_{n}-2 ; t_{n}-1\right)\left(t_{n}-2 ; t_{n}-1\right)$ не произойдет дефолт.

Значит, произведение $\prod_{2}^{n} P\left(t_{n-2,}, t_{n-1,}\right)$ выражает вероятность того, что не произойдет дефолт до начала периода $n$.

Таким образом, в формуле (11) суммируется приведенный платеж по CDS, умноженный на вероятность его совершения.

Кроме того, необходимо оценить платежи за защиту в период $\tau-t_{n}-$ время от совершения последнего платежа до дефолта. Поскольку распределение дефолтов между платежами считается равномерным, то в среднем дефолт должен произойти посередине периода. Поэтому приведенная стоимость единоразовой выплаты половины $s$ в случае дефолта в периоде $\mathrm{n}$ рассчитывается по формуле:

(12)

$$
S_{\text {HER }}=\sum_{n=1}^{N}\left(\prod_{2}^{n} P\left(t_{n-2}, t_{n-1}\right)\right) * \sqrt{P\left(t_{n-1}, t_{n}\right)} *\left(1-P\left(t_{n-1}, t_{n}\right)\right) * 0.5 * s * e^{-m(n-1 / 2)} .
$$

Обозначения те же.

$$
\begin{aligned}
& \sqrt{P\left(t_{n-1}, t_{n}\right)} \text { - выражает вероятность, что дефолт не произойдет до середины периода } n \text {. } \\
& \left(1-P\left(t_{n-1}, t_{n}\right) \text { - выражает вероятность наступления дефолта в период } n\right. \text {. }
\end{aligned}
$$

По аналогии с предыдущей формулой мы оценим приведенную стоимость платежа, которую получит покупатель защиты CDS в случае наступления дефолта:

$$
P_{n}^{d}=\sum_{n=1}^{W W}\left(\prod_{2}^{n} P\left(t_{n-2}, t_{n-1}\right)\right) * \sqrt{P\left(t_{n-1}, t_{n}\right)} *\left(1-P\left(t_{n-1}, t_{n}\right)\right) *(1-\delta) * \mathrm{e}^{-m(n-1 / 2)}
$$

где $\delta$ - коэффициент покрытия.

Следовательно, $(1-\delta)$ - платеж продавца защиты в случае дефолта.

Как было сказано, условием определения «справедливой» цены по CDS является равенство ожидаемых потоков покупателя и продавца CDS. Таким образом, цена CDS определяется решением следующего уравнения относительно $s$ :

$$
S_{n}+S_{\hat{I} \hat{E} \ddot{A}}=P_{n}^{d}
$$

Заметим, что единственным оценочным параметром в данной модели является коэффициент покрытия $\delta$. Он отражает, сколько будет стоить в процентах от номинала базовый актив, в нашем случае дисконтная облигация, сразу после наступления дефолта. Разницу между номиналом и стоимостью облигации после дефолта в заранее оговоренный день расчетов уплачивает продавец CDS покупателю. Данный параметр напрямую влияет на стоимость CDS, поскольку, если переоценить покрытие в случае дефолта, то стоимость CDS будет заниженной, и наоборот. Мы использовали коэффициент покрытия, равный 0,4, именно такое значение наиболее часто применяется в западных работах. В российской практике количество дефолтов крупных компаний небольшое, и сложно оценить этот коэффициент для такой компании, как «Газпром», например, поэтому мы решили использовать значение 0,4 .

Также необходимо обратить внимание на следующие важные аспекты данной модели: временную структуру процентных ставок и безрисковую ставку.

Поскольку необходимо рассчитывать вероятность дефолта по периодам на основе временной структуры процентных ставок, для точности модели необходимо правильно сконструировать кривую процентных ставок. Так как рассчитывается вероятность дефолта в 
каждом периоде - $P\left(t_{n-1}, t_{n}\right),-$ необходимо иметь структуру безрисковых и рисковых ставок на начало и конец каждого периода, то есть фактически знать цены рисковой и безрисковой облигаций на начало и конец периода.

Наиболее очевидным способом построения кривой доходностей или спредов является построение на основе рыночных цен дисконтных облигаций различной срочности, а уже на их основе можно построить кривую форвардных спредов. Но компании достаточно редко выпускают дисконтные облигации, поэтому построить кривую временной структуры их доходностей на основе рыночных данных практически невозможно. Таким образом, кривую форвардных процентных ставок необходимо моделировать, то есть строить косвенным путем, а не только на основе рыночной доходности дисконтных облигаций.

Для расчета бескупонных доходностей, на основе которых и рассчитывается стоимость CDS, мы использовали метод бутстрэппинга. Безрисковую кривую спот-ставок мы взяли из Блумберга, поскольку в качестве безрисковой использовалась кривая доходностей гособлигаций США.

Кривую спот-ставок компании мы рассчитывали на основе доходностей еврооблигаций. Поскольку каждая из компаний имеет публичный долг в долларах США и исследуемые CDS номинированы в долларах США, выбор доходностей евробондов представляется наиболее подходящим. Поскольку бутстрэппинг является общепринятым методом построения кривой бескупонных ставок и широко описан в литературе, детали его реализации в программе Excel мы приводить не будем.

На основе стоимости рисковой и безрисковой бескупонной облигации, применяя формулу (4), мы рассчитали вероятности дефолта компании за период. Используя формулы $(5),(6),(7)$ и разрешив равенство (8) относительно $s$, мы рассчитали значение CDS по каждой отдельной компании.

\section{Результаты применения моделей и выводы}

Модель Мертона и редуцированная модель были реализованы в приложении VBA Excel. Поскольку количество полученных точек по каждой модели - более 300, мы не будем приводить результаты расчетов в виде таблицы, а приведем их в виде графиков.

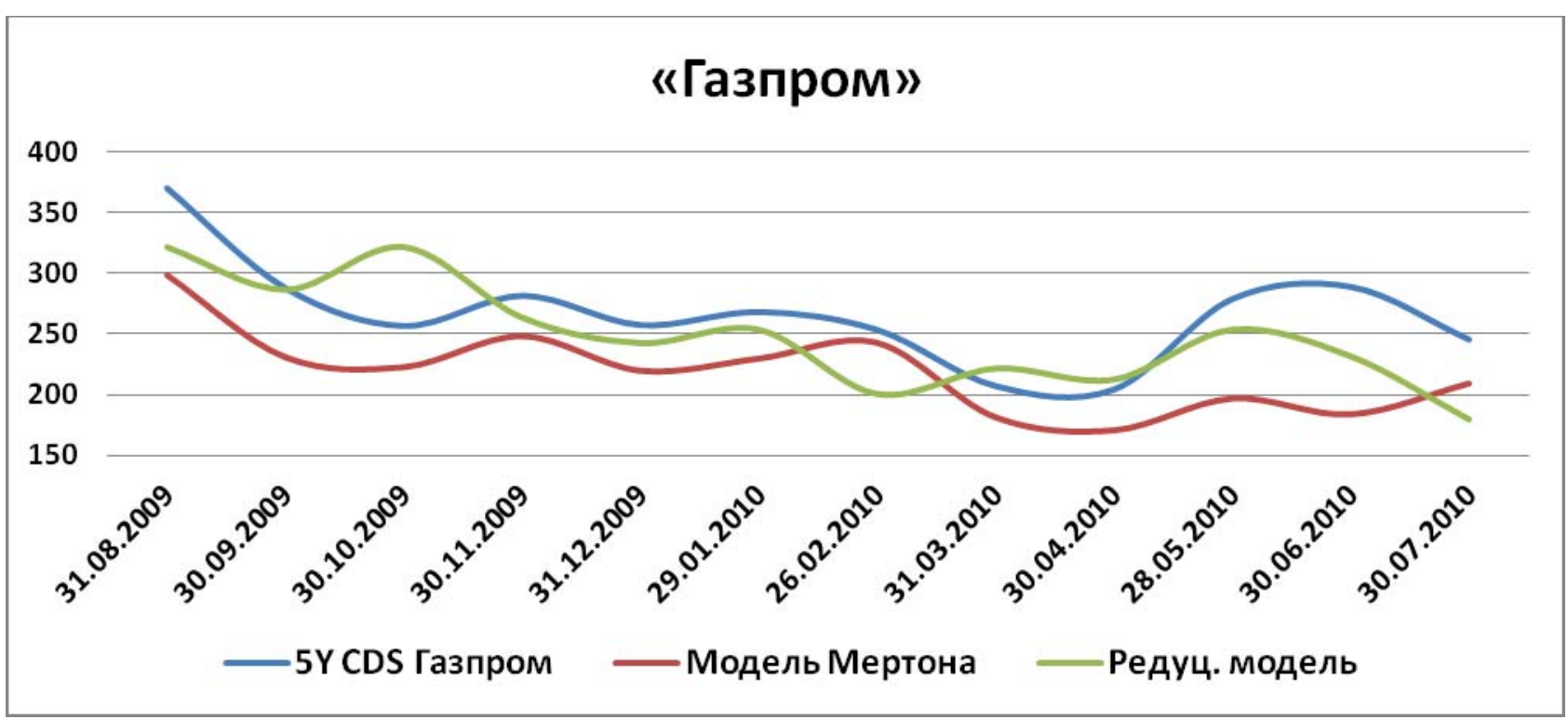

График 2. Результаты оценки CDS на «Газпром» 


\section{«Сбербанк»}

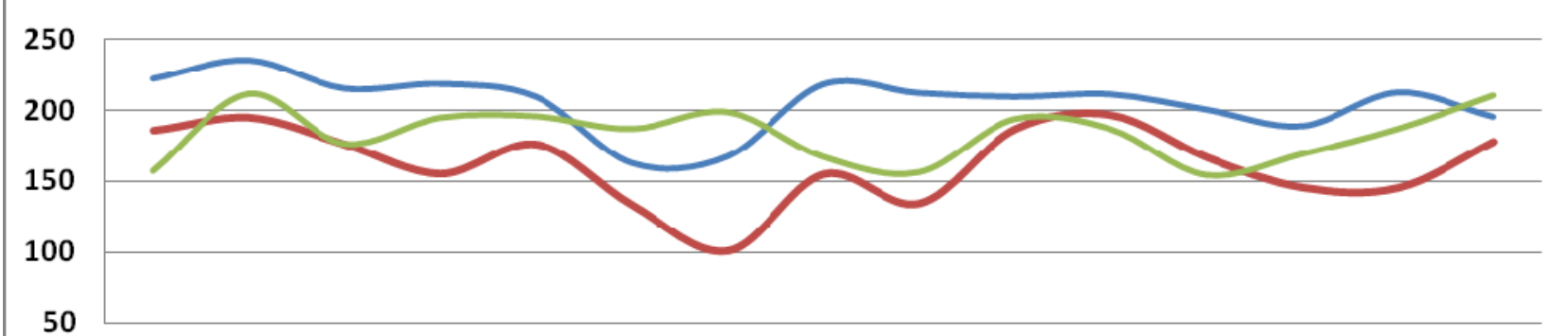

50

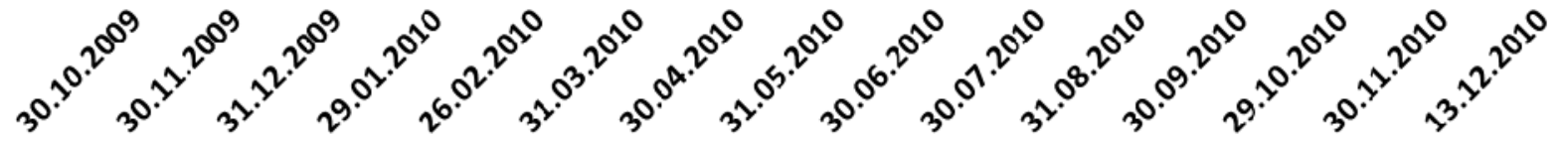

-5Y CDS Сбербанк

— Модель Мертона

Редуц. модель

График 3. Результаты оценки CDS на «Сбербанк»

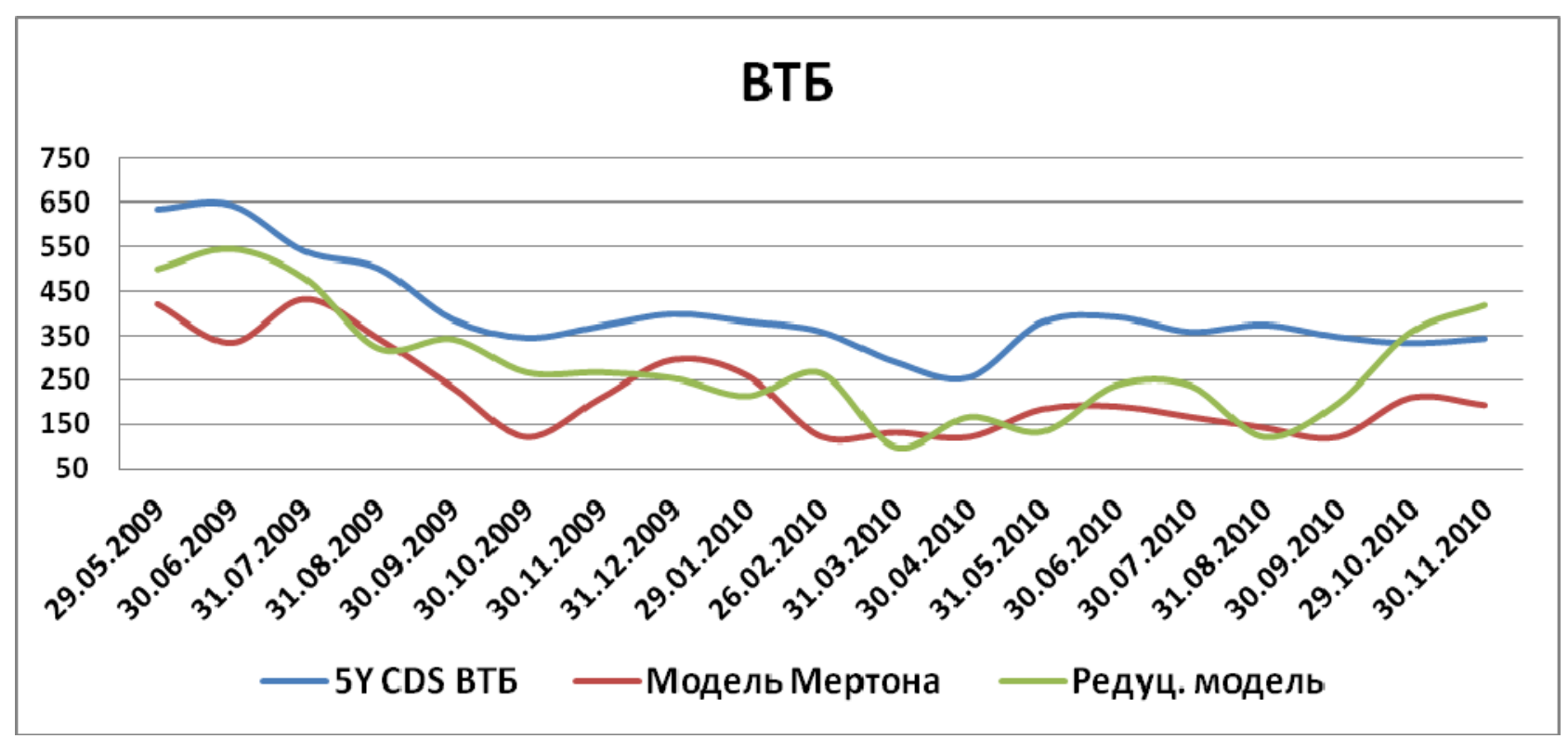

График 4. Результаты оценки CDS на ВТБ

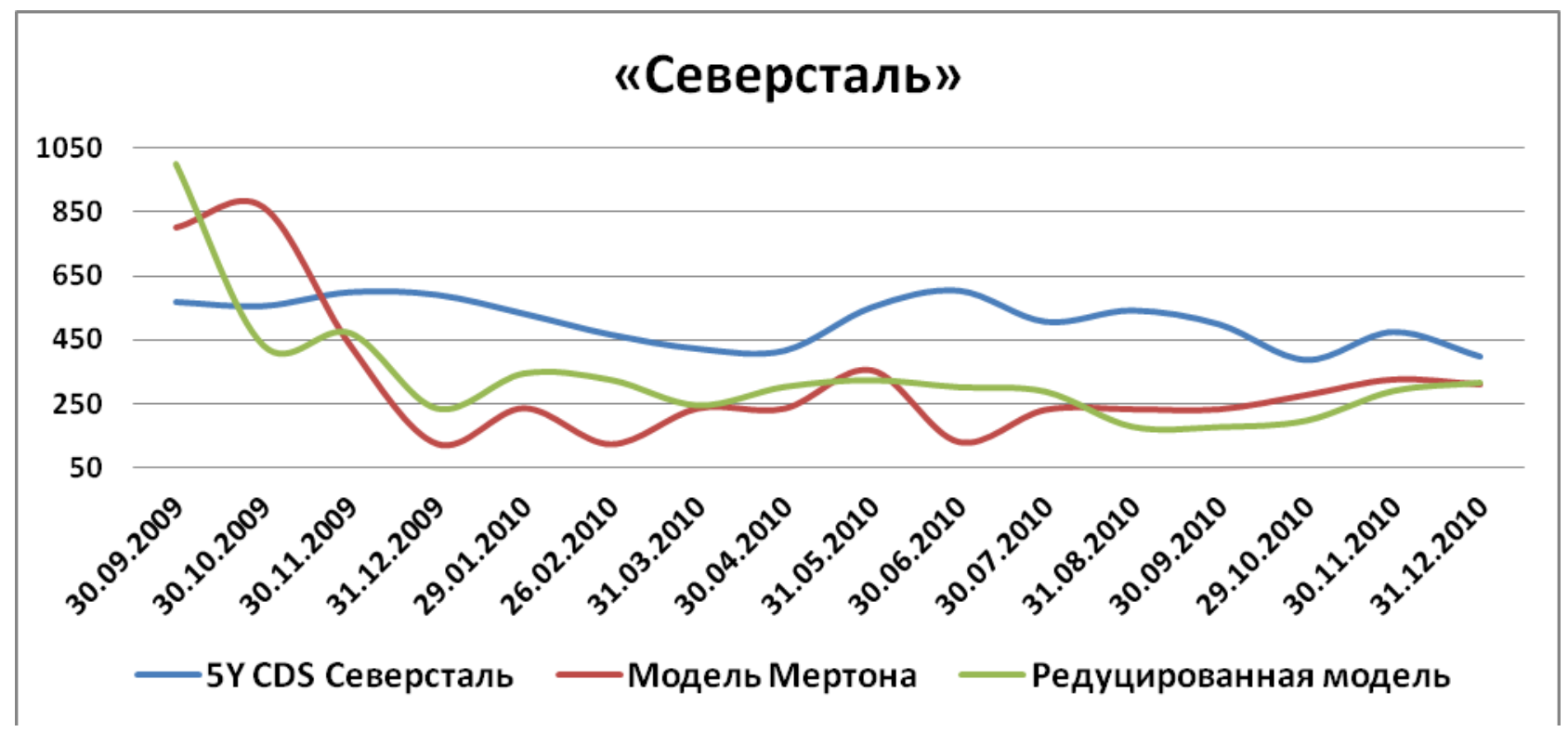

График 5. Результаты оценки CDS на «Северсталь» 


\section{«Транснефть»}

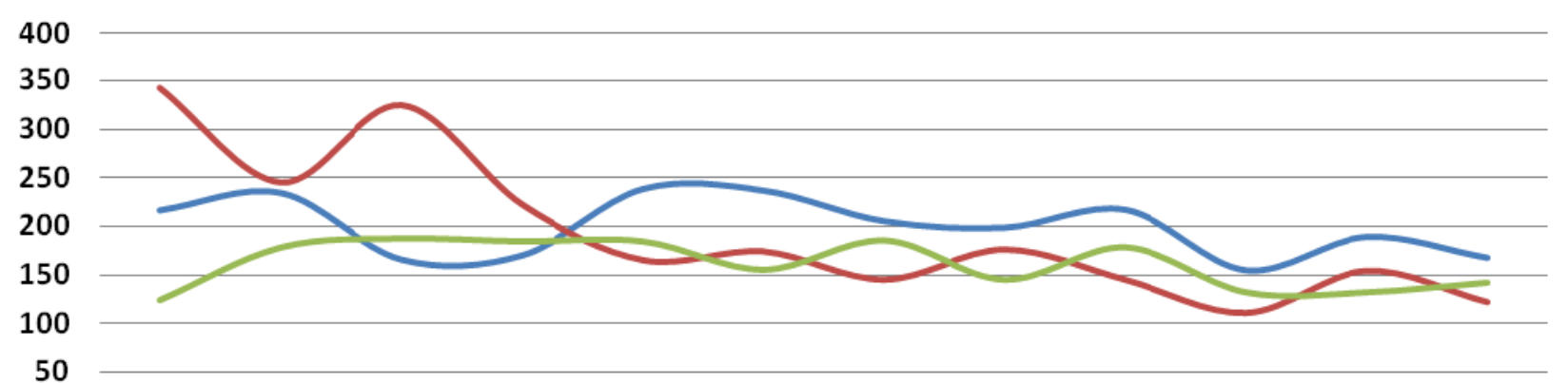

50

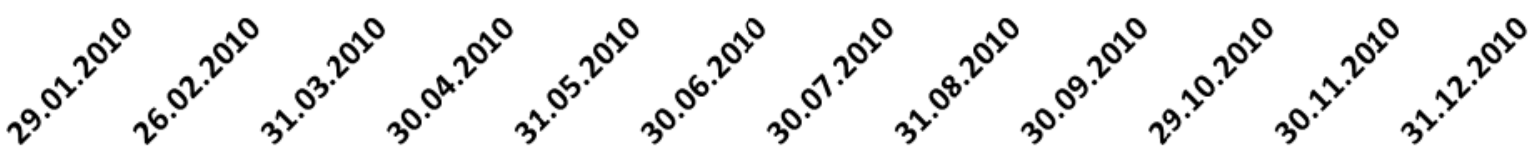

—5Y CDS Транснефть — Модель Мертона

- Редуцированная модель

График 6. Результаты оценки CDS на «Транснефть»

Чтобы количественно оценить точность той или иной модели, мы провели регрессионный анализ полученных с помощью моделей данных. В таблице 3 приведен пример регрессионного анализа результатов модели Мертона для компании «Газпром».

Регрессионный анализ

Таблица 3

\begin{tabular}{|c|c|c|c|c|}
\hline \multicolumn{2}{|c|}{ Регрессионная статистика } & \multirow{2}{*}{\multicolumn{2}{|c|}{ Модель Мертона. «Газпром» }} & \\
\hline Множественный R & 0,994999158 & & & \\
\hline R-квадрат & 0,990023323 & & & \\
\hline Нормированный & & & & \\
\hline квадрат & 0,899114233 & & & \\
\hline Стандартная ошибка & 28,13817573 & & & \\
\hline Наблюдения & 12 & & & \\
\hline \multicolumn{5}{|l|}{ Дисперсионный анализ } \\
\hline & $d f$ & $S S$ & $M S$ & $F$ \\
\hline Регрессия & 1 & 864259,365 & 864259,365 & 1091,571578 \\
\hline Остаток & 11 & 8709,326264 & 791,7569331 & \\
\hline \multirow[t]{2}{*}{ Итого } & 12 & 872968,6912 & & \\
\hline & Коэффициченть & $\begin{array}{l}\text { Стандартная } \\
\text { ошибка }\end{array}$ & $\begin{array}{l}t \text { - } \\
\text { статистика }\end{array}$ & Р-Значение \\
\hline Y-пересечение & 0 & \#Н/Д & \#Н/Д & \#Н/Д \\
\hline Переменная X 1 & 1,208155032 & 0,036567608 & 33,03894033 & $2,33158 \mathrm{E}-12$ \\
\hline
\end{tabular}

В таблице 4 объединены необходимые нам значения по всем компаниям и моделям.

Таблица 4

Результаты регрессионного анализа

\begin{tabular}{|c|c|c|c|}
\hline Модель & Компания & р-значение & Ст. ошибка \\
\hline \multirow{3}{*}{$\begin{array}{c}\text { Модель } \\
\text { Мертона }\end{array}$} & «Газпром» & 0,00000 & 28 \\
\cline { 2 - 4 } & «Сбербанк» & 0,00000 & 25 \\
\cline { 2 - 4 } & ВТБ & 0,00000 & 97 \\
\cline { 2 - 4 } & «Транснефть» & 0,00000 & 76 \\
\hline
\end{tabular}




\begin{tabular}{|c|c|c|c|}
\hline & «Северсталь» & 0,00002 & 280 \\
\hline \multirow{4}{*}{$\begin{array}{c}\text { Редуцированная } \\
\text { модель }\end{array}$} & «Газпром» & 0,00000 & 38 \\
\cline { 2 - 4 } & «Сбербанк» & 0,00000 & 30 \\
\cline { 2 - 4 } & ВТБ & 0,00000 & 112 \\
\cline { 2 - 4 } & «Транснефть» & 0,00000 & 38 \\
\cline { 2 - 4 } & «Северсталь» & 0,00000 & 243 \\
\hline
\end{tabular}

На основе таблицы 4 и графиков с результатами, полученными с помощью редуцированной модели и модели Мертона, можно сделать следующие выводы:

- Наиболее точно модель Мертона описывает изменение стоимости CDS на «Газпром» и «Сбербанк», в обоих случаях значение стандартной ошибки меньше, чем у других компаний.

- Редуцированная модель также лучше всего описывает стоимость CDS «Газпрома» и «Сбербанка».

-Исходя из графиков, теоретические спреды CDS, рассчитанные как с помощью модели Мертона, так и с помощью редуцированной модели, практически всегда ниже реальных спредов: все константы положительны и значимы (кроме структурной модели для «Газпрома»). То есть модели предполагают более низкую вероятность дефолта, чем участники рынка. Вполне возможно, что участниками закладываются дополнительные рискфакторы, не учитываемые моделями, например страновой риск.

- Как для ВТБ, так и для «Северстали» обе модели результата не показали. В обоих случаях модели показывают большое значение стандартной ошибки.

Делая вывод, можно сказать, что наилучшие результаты показала модель Мертона для прогнозирования стоимости CDS на компании «Газпром» и «Сбербанк». Но использованные нами модели оценки CDS являются классическими вариантами структурных и редуцированных моделей. Мы считаем, что существует ряд направлений, реализуя которые на перечисленных базовых моделях, можно улучшить точность оценки CDS. B редуцированных моделях точность зависит от «правильности» построения кривой кредитного спреда и оценки коэффициента покрытия. Кроме бусттрепинга можно использовать сплаин-метод для оценивания срочной структуры процентных ставок, предложенный впервые Маккаллохом (McCulloch, 1971). Либо использовать параметрические методы построения кривой кредитного спреда: константные, линейные квадратичные кривые или моделируемые кривые. Для коэффициента покрытия существует множество различных способов оценки: метод Монте-Карло, модель Альтмана, статистическая оценка на основе исторических данных о стоимости долговых активов после дефолта.

Модель Мертона очень чувствительна к оценке волатильности. Поэтому в редуцированной модели для оценки опциона на стоимость фирмы вместо модели БлекаШоулса можно применить модель Хестона, модель Бьерксунда-Стенслэнд, модель КоксаРубинштейна или модель Ятса. Вполне вероятно, что, применяя модель оценки опционов, отличную от модели Блека-Шоулса, мы сможем увеличить точность оценки. Кроме того, модель Мертона предполагает использование исторической волатильности.Применяя подразумеваемую (с англ. implied) волатильность, основанную на рыночной стоимости опциона, вероятно, можно получить более точные результаты, поскольку подразумеваемая волатильность - это будущая волатильность инструмента, оцениваемая участниками рынка в данный момент времени. Также вместо доходности бескупонной казначейской облигации США, используемой в качестве безрисковой ставки, можно использовать ставку Либор (с англ. LIBOR - London Interbank Offered Rate) различного срока либо ставку межбанковского РЕПО. Хотя последние две ставки не являются в полном смысле слова безрисковыми, они больше используются участниками рынка в качестве условно безрисковых, поэтому при их применении также возможно увеличение точности модели Мертона оценки CDS на 
компанию.

Также стоит заметить, что оба типа моделей требуют «проторгованных» инструментов. Это почти то же, что и ликвидные инструменты, но кроме ликвидности (объема торгов и размера спреда) инструмент должен обладать продолжительной историей торгов, быть объектом глубокого анализа широкого круга аналитиков и трейдеров, чтобы цены его инструментов быстро отражали реальное изменение дел. В отличие от этого, зачастую компания и ее инструменты «живут» отдельной жизнью, и менее десятка российских компаний обладают достаточно ликвидными долговыми инструментами и акциями, чтобы к ним можно было применить структурные или редуцированные модели.

Реализация вышеописанных модификаций моделей для оценки CDS на российские компании, а также учет эффекта низкой ликвидности и неэффективности рынка в отдельном инструменте может быть очень интересной и полезной задачей для дальнейших исследований.

\section{Список литературы}

1. Black, F., and Cox, J. (1976), Valuing Corporate Securities: Some Effects of Bond Indenture, Provisions, Journal of Finance, 31 (1976) 351-367.

2. Black, F., and Scholes, M. (1973), The Pricing of Options and Corporate Liabilities, Journal of Political Economy, 81 (1973) 637-659.

3. Duffie, D. (1999), Credit Swap Valuation, Financial Analysts Journal, 55 (1999) 73-89.

4. Duffie, D., and Singleton, K. (1999), Modeling Term Structures of Defaultable Bonds, Review of Financial Studies, 12 (1999) 687-720.

5. Eom, Y.H., Helwege, J., and Huang, J. (2000), Structural Models of Corporate Bond Pricing:An Empirical Analysis, Working Paper No/ 16, Pennsylvania State University.

6. Gemmill, G. (2002), Testing Merton's Model for Credit Spreads on Zero-coupon Bonds, Working paper, City University Business School, London.

7. Hull, J., Predescu, M., and White, A. (2002), The Relationship between Credit Default Swap Spreads, Bond Yields, and Credit Ratings Announcements, Working paper, University of Toronto.

8. Hull, J., and White, A. (2000), Valuing Credit Default Swaps I: No Counterparty Default Risk, Journal of Derivatives, 8 (2000) 29-40.

9. Jones, Ph.E., Scott, P.M., and Rosenfeld, E. (1984), Contingent Claims Analysis of Corporate Capital Structures: An Empirical Investigation, The Journal of Finance 39 (1984) 611-625.

10. Kealhofer, S. (2003a), Quantifying Credit Risk I: Default Prediction, Financial Analysts Journal, 1(59) (2003a) 30-44.

11. Kealhofer, S. (2003b), Quantifying Credit Risk II: Debt Valuation, Financial Analysts Journal, 3(59) (2003b) 78-92.

12. Litterman, R., and Iben T. (1991), Corporate Bond Valuation and the Term Structure of Credit Spreads, Journal of Portfolio Management, 17 (1991) 52-64.

13. Longstaff, F.A., and Schwartz, E. (1995), A Simple Approach to Valuing Risky Fixed and Floating Debt, Journal of Finance, 50 (1995) 789-819.

14. Longstaff, F.A., Mithal, S., and Neis, E. (2003), The credit-default swap market: Is Credit Protection Priced Correctly?, Working paper.

15. McCulloch, J.H. (1971), Measuring the Term structure of interest Rates, Journal of Business, 44 (1971) 19-31.

16. Merton, R.C., On the Pricing of Corporate Debt: The Risk Structure of Interest Rates, Journal of Finance, 29 (1974) 449-470.

17. Merton, R.C., Option Pricing When Underlying Stock Returns are Discontinuous, Journal of Financial Economics, 3 (1976) 125-144. 